\title{
CREADORAS EN LA DRAMATURGIA FEMENINA DE LOS SIGLOS DE ORO Y SUS MECANISMOS DE METATEATRALIDAD PARA REACCIONAR CONTRA LO ESTABLECIDO: ANA CARO
}

\author{
WOMEN CREATORS IN THE FEMININE DRAMATURGY OF THE GOLDEN \\ CENTURIES AND THEIR METHATRALITY MECHANISMS TO REACT AGAINST \\ THE ESTABLISHED PRACTICES: ANA CARO
}

\author{
María José Rodríguez Campillo \\ Universitat Rovira i Virgili
}

\begin{abstract}
Resumen:
El objetivo principal de este artículo es realizar un análisis y posterior reflexión acerca del metateatro que podemos encontrar, de forma bastante abundante y sistemática, en la dramaturgia de Ana Caro. Así, pretendemos analizar sus obras teatrales, para demostrar cómo ella, bajo variadas estrategias metateatrales, nos está enviando un mensaje cuya ideología es distinta al de la misma época dentro del teatro escrito por hombres. La conclusión que extraemos en este artículo es que no está conforme con la manera de hacer teatro ni con la forma de pensar que tienen los hombres de su época y, por eso, intenta transgredir esas normas a través de la metateatralidad.
\end{abstract}

\section{Palabras Clave:}

metateatro, escritoras, Siglos de Oro, Ana Caro

\section{Abstract:}

The main objective of this article is to carry out an analysis and subsequent reflection about the meta-theater that we can find, in a quite abundant and systematic way, in Ana Caro's dramaturgy. Thus, we intend to analyze her theatrical works, to show how she, under various meta-theatrical strategies, is sending us a message whose ideology is different from that of the same period within the theater written by men. The conclusion that we draw in this article is that she is not satisfied with the way of doing theater or with the way of thinking that the men of her time have and, therefore, she tries to transgress those norms through meta-theater.

\section{KeYwORDs:}

metatheatre, women's writing, Golden Age, Ana Caro 


\section{INTRODUCCIÓN}

La metateatralidad supone una simultaneidad de planos teatrales, sea cual sea la estrategia empleada: obra dentro de la obra, uso de ceremonias, personaje que juega otro rol, el disfraz varonil, por ejemplo (Bel Enguix, Jiménez López y Rodríguez Campillo 2011), referencias literarias o de la vida real, autorreferencias, etc. En este artículo analizamos los distintos mecanismos metateatrales que se utilizan en el teatro femenino de los Siglos de Oro y lo ejemplificamos con la obra de una dramaturga sevillana, Ana Caro.

A través del metateatro, esta dramaturga áurea nos invita a una lectura de sus obras como si estas fueran, más que una comedia, una preceptiva dramática, como si fueran una crítica o denuncia a las convenciones teatrales del momento. Ella tiene conciencia de autoría y sabe que está creando algo nuevo, nos está enviando un mensaje nuevo, y una de las formas para hacerlo es a través de la metateatralidad.

La metaliteratura no es nada nuevo en los Siglos de Oro, pues recordemos que Miguel de Cervantes la utiliza ya en su obra más conocida, El Quijote (en la famosa quema de libros que hacen el cura y el barbero, por ejemplo). Lo que va a suceder ahora es que esta dramaturga va a utilizar el recurso con una finalidad específica $y$, por tanto, la lectura que podemos y debemos hacer de sus obras va a ser doble: una explícita y otra implícita.

Por ello, en este trabajo trataremos de desvelar, como dice López de Abiada, "todas aquellas parcelas de sentido que quedan veladas o expresadas de manera implícita (...) pero que se hallan presentes en el texto escrito" (1997: 44); unas parcelas introducidas a través de distintos mecanismos metateatrales que, en cierta manera, están violando la normativa establecida entonces y, por ello, nos envían un mensaje distinto al habitual (López de Abiada 1996).

El corpus que se ha utilizado para analizar las distintas estrategias metateatrales que se utilizan en el teatro femenino de los Siglos de Oro son las obras de la dramaturga Ana Caro, Valor, agravio y mujer' (Caro 1993) y El conde Partinuplés ${ }^{2}$ (1977). Son, por tanto, dos obras, las que sirven de corpus para el análisis que pretendemos hacer sobre la metateatralidad en la dramaturgia femenina áurea.

A partir de los años sesenta del siglo XX, y con Lionel Abel (1963) a la cabeza, se inicia el interés por el término "metateatro" y todo lo que él mismo implica, sobre todo por la necesidad de atender a un fenómeno artístico cada vez más presente en las obras de los renovadores de la escuela teatral europea del siglo XX como fueron Pirandello, Beckett o Brecht, entre otros.

1 A partir de ahora Valor

2 A partir de ahora Conde 
Abel titula su conocida obra Metateatro pues, según él, este es el tipo de teatro que se está empezando a gestar en la época y que él mismo considera el relevo de las antiguas tragedias.

Después de él, este término empezó a ser objeto de diversos análisis, más o menos sistemáticos. De todos ellos, hay algunos que han de ser tomados como referencia por cualquier estudioso del tema. Estos son: Abel (1963), Metatheatre: A New View of Dramatic Form; Schlueter (1979), Metafictional Characters in Modern Drama; Schmeling (1982), Métathéatre et intertexte; Hornby (1986), Drama, Metadrama and Perception; y Gray (2011), Claves y estrategias metateatrales.

En el contexto español, al principio, los pocos estudiosos que han centrado su interés en el metateatro lo han hecho, casi siempre, limitándose única y exclusivamente al análisis de un autor determinado y a su utilización, o a algo más general y su intento de definición. Aunque también hay que señalar que, en los últimos treinta años, ha crecido el interés de distintos investigadores del género teatral, sobre todo por el metateatro áureo. Algunos de los estudiosos más representativos son: Abuín (1996, 1997), Arboleda (1990), Balestrino (2011), Courdec (2010), Ebersole (1988), García Barrientos (2012), Garrot (2010), Hermenegildo (1999), Larson (1989), Pavis (1998), y Sosa y Balestrino (2011)³.

Estos estudios pueden ser considerados (Gray 2011) como la base de la teorización del metateatro, aunque con algún que otro defecto, como el de analizarlo casi exclusivamente dentro de las formas más tradicionales del teatro, dentro de los paradigmas tradicionales.

\section{Metateatro}

\subsection{Definición Y FINALIDAD}

El forjador del término, por cronología y adeptos, como ya hemos podido ver, es Lionel Abel. Así lo reconocen García Barrientos (2012: 234), Abuín González (1997: 199), Patrice Pavis (2002: 289) y Hornby (1986: 31), a pesar de que Abel, como nos recuerda Hornby (1986: 31), no llega a definir el término como tal, pues su primera obra, la de 1963, es simplemente una compilación de artículos heterogéneos sobre distintas obras que, eso sí, él mismo considera metateatrales (Abel 1963: 60). Por consiguiente, como estas obras nuevas son la realización concreta del género metateatral, las llama metaobras (Abel 1963: 61), no sin antes concluir que la tragedia clásica y el metateatro constituyen dos géneros teatrales que han convivido durante largo tiempo aunque, en la actualidad, el metateatro tome el relevo del género clásico. Y, para demostrar esta convivencia, Abel presta atención, principalmente, a Shakespeare (con Hamlet) y a Calderón (con La vida es sueño) porque, desde su punto de vista, las dos obras de estos

3 Datos ampliados en bibliografía final. 
conocidos dramaturgos y su época (el siglo XVII) son los verdaderos iniciadores del metateatro (Abel 1963: 58).

Abuín, al hablar del metateatro, menciona que este "llama la atención sobre su status como artefacto, poniendo al descubierto convenciones vacías de todo sentido, llevando a su espectador a cuestionar la relación entre ficción y realidad" (Abuín 1996: 19-20) y, así, "explorando sus estructuras ficticias, tales obras exploran también la «ficcionalidad» del mundo real, la «realidad» del mundo ficticio" (Abuín 1997: 199).

Hermenegildo (2002: 2013) dice que es el "Teatro en el Teatro" y que englobaría, desde la estructura encuadrante hasta el personaje dentro del personaje.

Por último, la definición de Arboleda (1991: 7), más modesta, menciona que, "en términos generales, el metateatro se ha considerado como una forma dramática de carácter reflexivo y autorreflexivo".

En la obra metateatral, por norma general, algunos personajes no hacen lo que se les encomienda, sino que se rebelan. De esta rebelión del personaje, en la obra metateatral surgen una serie de implicaciones más trascendentales, como el cuestionamiento del orden establecido, las autorreferencias, las autorreflexiones, los intertextos, el teatro dentro del teatro, etc.; en definitiva, todo aquello que sirva para hacer cambiar a la audiencia la percepción habitual de las cosas. Y ello sucede porque, según estos primeros autores, el metateatro tiene una finalidad concreta, que es la de pretender cambiar la percepción tradicional que el público tiene de la realidad, pues persigue revelarnos la verdad oculta de algunos mecanismos convencionales de los que se sirve el teatro y, gracias a él, se nos pone en aviso, nos enteramos de sucesos históricos ocultados, o de situaciones injustas, por ejemplo. Por ende, el metateatro cumple una función más o menos revolucionaria, pues pretende cambiar la percepción tradicional que el público tiene de la realidad: ese es su fin último.

El metateatro no es un fenómeno que está limitado a una serie de autores o a un periodo histórico determinado, sino que "es cultivado por numerosos autores en todas las épocas" (Hornby 1986: 26). Sin embargo, y como es lógico, su grado de utilización cambiará dependiendo de "la mente creadora a lo largo de los momentos históricos" (Hornby 1986: 26). Unos momentos históricos que Schmeling (1982: 20) llega incluso a establecer y que, en terminología del propio autor son: 1) el clasicismo del XVII, 2) el racionalismo del siglo XVIII y 3) el realismo/naturalismo del siglo XIX.

De esta manera, la mayoría de los investigadores coincide en que es en el siglo XVII (el primero de los períodos establecidos por Schmeling) cuando se inicia el metateatro como tal, y que lo hace de la mano de Shakespeare y Calderón, a los que Abel (1963) ya prestó también atención. A partir de esta época, el recurso en sí va a ir adquiriendo connotaciones de puro juego, irónicas. Por ende, en la obra teatral "el escenario se 
desvela como un juego de estrategias constantes dirigidas a la figura del espectador [...] ¿Cómo se percibe la existencia de tales juegos? Muchas veces por la ruptura de las fronteras prohibidas entre lo real y lo imaginario [...]. La escena manifiesta una abierta tendencia a la autorreferencia, uno de los rasgos que suprime la ilusión y promueve la aparición de una obra autoconsciente" (Aubín 1996, 14-15).

Arboleda (1990,1991) y Jódar (2016), apuntan a que Cervantes debe ser considerado el primer teorizador metateatral. Esta vertiente parece venirle, al mismo Cervantes, de la Commedia dell'Arte italiana, tan importante e influyente en la época cervantina. Sin embargo, no debemos restarle mérito al propio autor, pues la autorreflexividad, aspecto metateatral importante, está en él desde siempre, ya que este gran autor criticó sistemáticamente el teatro de su época, sobre todo centrándose en la figura de Lope, al que enjuiciaba su mercantilismo en pro de la calidad de sus obras.

Abel (1963), Arboleda (1991) y Jódar (2016) explican esta voluntad subversiva de Cervantes como encadenada al momento histórico que le tocó vivir, la España prebarroca. De esta manera, el metateatro (y más en concreto la metaliteratura) es utilizado por Cervantes en varias de sus obras y lo emplea para parodiar determinados asuntos, como sucede en su Retablo de Maese Pedro donde, en el fondo, Cervantes llega a cuestionar todo el teatro de su época, ese que está tan de moda. Así, al criticar y reflexionar sobre este teatro, él mismo nos "va exponiendo su teoría metadramática" (Arboleda 1991: 65).

Por todo ello, y por autores como Cervantes, el Barroco "se convierte en el momento de madurez y desarrollo de la técnica metateatral, debido al cambio de mentalidad que se está produciendo en la época" (Jódar 2016: 66) y a la modernización del pensamiento, "y esta es la razón por la cual el metatetaro, a pesar de ser una técnica harto conocida desde los inicios del arte teatral, no encuentra su desarrollo hasta el momento" (Garrot 2010: 10).

Pero si Cervantes es el iniciador del metateatro en la literatura castellana, Garrot erige a Calderón como el máximo cultivador de las técnicas metateatrales en dicha época; unas técnicas "que tanto predominaban en el teatro clásico español, merced a la dimensión trascendente que adquirían" (2010: 11), y unas técnicas que, como veremos, Ana Caro también va a utilizar en sus obras en beneficio propio.

2.2. Mecanismos de metateatralidad

A la hora de establecer las diferentes manifestaciones de este hecho teatral y sus principales estrategias, los distintos estudiosos del tema oscilan un poco sobre cuáles pueden ser estas. Sin embargo, todos están de acuerdo en que la primera y más importante de las categorías metadramáticas es la del "Teatro dentro del Teatro". 
Dicen de ella que es el mecanismo más reconocido por presentar una obra inserta dentro de otra, que es la obra marco.

Couderc (2010) menciona que los procedimientos típicos del metateatro son: la mise en abysme, la teatralización de la vida y la autorreflexividad (en Jódar 2016: 66) y que, además, estos procedimientos son típicamente barrocos, pues casan muy bien con la ideología y características propias del siglo XVII. Schmeling establece una morfología de formas metateatrales y habla de estrategias, técnicas o formas autorreflexivas, intertextuales y del "Teatro dentro del Teatro" (1982: 3). García Barrientos (2012) hace una clasificación más simple, entre dos grandes parcelas, el metateatro (Teatro dentro del Teatro) y el metadrama, con el resto de recursos metaficcionales. Y, por último, Abuín (1996: 13-14) habla de autoconsciente (con los coros de las tragedias griegas, los prólogos, los epílogos o los apartes) autorreflexivo y autorreferencial (cuando habla de sus convenciones institutivas).

Ante tal variedad terminológica, que no hace más que dar cuenta de la gran diversidad de procedimientos metateatrales que puede haber, en este artículo se analizarán los mecanismos de teatralidad que consideramos más representativos de la dramaturgia femenina áurea, y que no son más que los que mencionan Couderc, Schmeling o Abuín, casi con su misma nomenclatura.

El primer mecanismo, por supuesto, será el “Teatro dentro del Teatro" y su subapartado, el "Papel dentro del Papel" o el personaje fingido. Seguidamente, trabajaremos las autorreflexiones (ya sean estas en forma de aparte, monólogo, soliloquio, ocasionales interpelaciones al público, guiños, etc.) y finalizaremos con las autorreferencias (ya sean estas en forma de alusiones, referencias a la literatura y a la vida real, reescrituras, etc.).

\subsubsection{El "Teatro dentro del Teatro"}

El empleo del "Teatro dentro del Teatro" procede del interés barroco por la mezcla de géneros y artes, así como por el gusto por el juego de perspectivas (Hernández 1988: 9). Además, la idea conecta también con la creación del nuevo género, la tragicomedia, justificada porque, en realidad, como dice Lope, lo cómico y lo trágico aparecen indisolublemente unidos en la naturaleza: “Lo trágico y lo cómico mezclado/ y Terencio con Séneca, aunque sea/ como otro Minotauro de Pasife,/ harán grave una cosa, otra ridícula,/ que aquesta variedad deleita mucho;/ buen ejemplo nos da la naturaleza,/ que por tal variedad tiene belleza" (Lope 2006, vv. 175-180).

Dentro de esta estrategia nos encontramos con un pequeño subapartado, el del "Personaje dentro del Personaje", el "Papel dentro del Papel", como lo llama Ebersole (1988: 8). Esta estrategia parece ser una técnica metateatral fundamental en nuestro teatro clásico, pues es el transmisor, entre otras muchas cosas, del tan conocido tema 
del engaño barroco (Hornby 1986: 82), de "la confusión típica del Barroco, porque los restantes personajes de la comedia no tienen conciencia de la falsedad de lo representado" (Hernández 1988-89:76).

La técnica es un arquetipo que crea su propia comedia dentro de la obra mediante una máscara o disfraz y "cuya función es manipular al resto de los personajes para llevar a cabo sus propios objetivos" (Ebersole 1988: 8). Así, Ebersole establece la diferencia entre los personajes fingidos, que lo son desde el inicio de la obra (en Valor los encontraremos) y los que aparecen en mitad de la misma: tan solo en el segundo caso estaríamos hablando, según él, del role-playing, "Papel dentro del Papel" o metateatro, "porque el fingido controla la acción de los demás, o provoca una reacción entre alguno que fuerza un cambio en la acción" (Ebersole 1988: 64).

El primero de estos personajes fingidos, el que lo es desde el principio de la obra, se puede encontrar, muy bien trabajado, en todo el teatro de la época áurea, tanto el escrito por hombres como por mujeres.

El recurso o motivo en sí consiste en que la mujer (casi siempre ella) se disfraza de hombre para que el público que va a ver representada la obra "disfrute" con ello, pues este sí que conoce el disfraz, frente a casi el resto de los personajes de la obra que lo ignoran. Con esto, lo que se hace es que se puedan provocar enormes equívocos, muy del gusto en el barroco. Por ello, quizá, Lope de Vega recomienda el procedimiento en su Arte Nuevo pero, eso sí, con la única finalidad de agradar al público: “Las damas no desdigan de su nombre, / y si mudaren traje, sea de modo / que pueda personarse, porque suele / el disfraz varonil agradar mucho" (Lope 2006, vv. 280 y ss.).

Para darnos cuenta de la popularidad que alcanzó esta técnica en la época decir que, de las más de cuatrocientas sesenta comedias que escribió Lope de Vega, este recurso aparece en unas ciento diez (casi la cuarta parte de su producción), Tirso lo utilizó en veintiuna ocasiones y Calderón, por ejemplo, en siete de las más de cien obras que compuso.

En las dos obras analizadas, este recurso aparece en ambas. Este motivo lo utiliza Ana Caro en Valor cuando hace aparecer en escena a Leonor vestida de hombre (Leonardo) para vengar una deshonra. Sin embargo, "el disfraz que convierte a Leonor en Leonardo consigue transformar a las personas que la rodean" (Risco 2005: 108). Ella misma nos lo dice: "mi agravio mudó mi ser" (verso 510)4. Con ello, creemos que nos hallamos ante una afirmación de identidad, de un cuestionamiento al más puro estilo existencialista.

La misma Caro utiliza este recurso en su otra obra, Conde, aunque aquí con menor impacto o fuerza reivindicativa, pues aparece Lisbela (que no es la protagonista de la obra) disfrazada

4 Se citan todas las obras por los versos de las ediciones analizadas que están recogidas en la bibliografía final. 
de hombre para intentar rescatar a alguien (en este caso concreto a un hombre) que, parece ser, se encuentra cautivo.

\subsubsection{Autorreflexividad}

Los diálogos, monólogos o apartes, por ejemplo, a modo de autorreflexiones, que encontramos en las obras teatrales en las que ciertos personajes suelen erigirse en portavoces de sus creadores y en donde se discute, la mayoría de las veces, la teoría lopesca sobre la Comedia Nueva, englobarían este subapartado de recursos o estrategias metateatrales.

Esta estrategia es la que, por ejemplo, utilizará Cervantes en El retablo de Maese Pedro, cuando pone en boca de sus personajes sus propias ideas acerca del teatro de la época, que no es nada más y nada menos que el mismo teatro que estamos analizando aquí.

Estos apartes, monólogos, soliloquios, ocasionales interpelaciones al público, guiños, etc., no son más que procedimientos habituales en todo el teatro barroco. Sin embargo, pueden considerarse también como variedades metateatrales en el momento en que llegan a romper la pared con el espectador, cuando tienen el objetivo de transmitir una idea al público distinta a la que este está acostumbrado.

De todos ellos, quizá el aparte sea el recurso más conocido. El aparte contiene, en la mayoría de los casos, una información cuyo destinatario puede ser el emisor mismo (aparte monologado), uno o más personajes de la escena (aparte dialogado) o el espectador (aparte dirigido al público o interpelación al público) (Izquierdo 1999: 126), aunque a estas últimas, las interpelaciones, sin embargo, algunos autores (Couderc 2010: 96) las consideran únicamente definitorias de géneros menores como las loa.

Con este recurso, los autores aluden, la mayoría de las veces, al contexto de producción de la obra, con el que no parecen estar muy de acuerdo y, así, nos (re) descubren el teatro, nos muestran el teatro por dentro.

Un claro ejemplo del recurso autorreflexivo, esta vez con una crítica a las convenciones dramáticas de la comedia de la época, lo podemos encontrar en Valor, de Ana Caro, donde el personaje Ribete (el gracioso) se queja, en un aparte, del hecho de tener que hacer el papel de cobarde por ser el gracioso de esta. En cierta manera, y si leemos su mensaje entre líneas, de lo que se está quejando o lo que está denunciando abiertamente Ribete ( $\mathrm{y}$, a través de él, su autora) es la convención que todos los que estamos acostumbrados a leer o ver teatro clásico tenemos, hecha a priori, de que los graciosos son "unos muertos de hambre" y unos cobardes o "gallinas": "RIBETE. Estoy mal con enfadosos / que introducen los graciosos / como muertos de hambre y gallinas" (vv. 529-531). 
En definitiva, se está quejando de los cánones que han establecido los dramaturgos de la época, cánones que las dramaturgas no quieren seguir tan estrictamente. Es, por tanto, una pequeña reivindicación solapada (puesta en boca del mismo gracioso y en un aparte) de lo que Ana Caro, en este caso, pensaba de la dramaturgia del momento hecha por los hombres. Es una crítica a ciertos comportamientos recurrentes, sobre todo en estos personajes tipo, y realizada a través de una estrategia metateatral.

En Conde, Caro vuelve a ofrecernos metateatralidad: se queja de la convención que se tiene de que los graciosos son cobardes, y lo hace, otra vez, en la figura del gracioso de la obra, Gaulín. Ahora, también vuelve a hacer una crítica implícita a la figura de este gracioso áureo y sobre las convenciones que, de ellos, como personajes de la comedia que eran, se tenía. Y, con un juego de palabras, típico, por otra parte, del gracioso, nos hace ver que no siempre han de ser cobardes, que también tienen su fuerza y valor: “GAULÍN. Vamos, aunque sea al abismo; / contigo al infierno mismo / no temeré, claro está; / porque es cierta conclusión, / que contradicción no implica / que quien anda en la botica / ha de oler al diaquilón" (vv. 819 y ss.).

Estamos, por tanto, ante una lectura implícita de lo que la autora nos quiere decir: una queja de las convenciones teatrales que, por ejemplo, ponen siempre a los personajes tipo de una determinada manera y, de ahí, ya no salen para evolucionar. Así, Gaulín se vuelve a quejar de que siempre, en todas las comedias de la época, cuando alguien ve a un gracioso, está pensando en su cobardía: él quiere (la autora, mejor) romper con ese tópico y lo hace con un refrán muy ilustrativo, como se ha podido ver, pues no siempre "quien anda en la botica / ha de oler al diaquilón" (vv. 819 y ss.).

\subsubsection{Autorreferencias}

En algunas obras teatrales, los personajes de estas se autocaracterizan y funcionan como verdaderos dramaturgos o directores dentro del mismo texto teatral, escribiendo nuevos argumentos o dirigiendo las acciones de otros personajes con una actitud obviamente autorreferencial, por ejemplo (Larson 1989, 1010).

Estas autorreferencias se pueden hacer a través de referencias a la vida real, a través de la literatura (Hornby 1986: 88), de las alusiones a la propia obra y a algunas características de esta, e incluso a través de reescrituras que la audiencia suele identificar fácilmente.

Estas características son las menos metadramáticas, pues su conocimiento depende del tipo de público que lea o vea la obra teatral (Hornby 1986: 100) y, por ejemplo, si son demasiado conocidas (biblia, mitología, folklóricas, etc.) no producen el efecto que se requiere y, por ello, no acaban de funcionar bien (Hornby 1986: 90). Su importancia metadramática estriba en que estas referencias o alusiones han de ser necesariamente 
directas y estar relacionadas con personajes del entorno de la audiencia o con obras de la actualidad para poder ser perfectamente reconocidas por esta.

Una alusión o referencia a la vida real, a la vida de esa época, la encontramos en Valor, en el momento en que Tomillo le pregunta a Ribete por Madrid y lo que está sucediendo allí: “RIBETE: (...) Ya es todo muy viejo allá; / solo en esto de poetas / hay notable novedad / por innumerables tanto / que aun quieren poetizar / las mujeres y se atreven / a hacer comedias ya" (vv. 1164-1170).

A lo que Tomillo, por supuesto, responde rápido y un poco asustado: “TOMILLO: ¡Válgame Dios! Pues ¿no fuera / mejor coser e hilar? / ¿Mujeres poetas?” (vv. 11711173).

En este diálogo, Ana Caro utiliza la técnica de la antítesis para, a través de lo que nos dicen estos dos personajes, criticar al teatro que se estaba haciendo en la época, al teatro masculino, un teatro que, para ellas, se ha quedado viejo. Lo viejo, por tanto, será el empleo de las "viejas" convenciones teatrales, y la "notable novedad" serán las subversiones que ellas hacen de las mismas.

Y sigue Ribete, en su conversación con Tomillo, mencionando el nombre de infinidad de mujeres cultas de la antigüedad en una clara referencia o apoyo a la literatura femenina ("más de un millar") para, así, poder disculpar lo novedoso de esta poeta y su "osadía" al atreverse a entrar en un mundo vedado a ellas. Volvemos, por tanto, a tener metateatro en el momento en que la autora se queja de la situación de las dramaturgas de la época y se apoya en autoras anteriores a ellas para demostrar que no son las primeras que se atreven a irrumpir en el mundo de las letras (y tampoco serán, por tanto, las últimas): “RIBETE. Sí; / mas no es nuevo, pues están / Argentaria, Sofoareta, / Blesilla, y más de un millar / de modernas, que hoy a Italia / lustre soberano dan, / disculpando la osadía / de su nueva vanidad" (vv. 1173-1180).

Por ende, nos encontramos con la utilización de un tópico literario puesto en boca del criado y solo para hacernos ver que ellas, las dramaturgas, también conocen la literatura del momento, que también saben utilizar a su conveniencia los tópicos que habían puesto de moda sus contemporáneos.

El resto de las referencias que aparecen en estas obras analizadas son mitológicas o folklóricas y, por tanto, demasiado conocidas en la época para producir el efecto deseado. Sin embargo, recogemos, como muestra, algunas de ellas, como las que aparecen en la obra de Caro, Valor, cuando se habla de Faetonte, hijo del Sol (verso 28), de Noto, uno de los cuatro vientos cardinales (verso 39); o las referencias a una obra de Lope de Vega, Las doncellas de labor (verso 71), a Mavorte, nombre propio arcaico y poético de Marte (verso 72), a El Burlador de Sevilla, de Tirso (verso 116 y siguientes) o, por finalizar ya, en los versos 131-135 una probable alusión a las aventuras quijotescas. 


\section{Conclusión}

La principal conclusión que se extrae del análisis metateatral realizado a estas obras de Ana Caro es que la dramaturga no está conforme, ni con la manera de hacer teatro ni con la forma de pensar que tienen los hombres de su época y, ella, intenta transgredir esas normas a través, por ejemplo, de la metateatralidad.

La función, por tanto, de dicha metateatralidad es cuestionar el género trazado por Lope de Vega y sus seguidores a partir de la Comedia Nueva.

A través de tres mecanismos metateatrales distintos se ha podido demostrar lo que piensa esta dramaturga sobre el teatro que se hacía en su época y que era:

- Un teatro que disfraza a sus personajes, pero no simplemente porque ello agrade al público, sino para demostrarnos que los roles de género son relativos y que su asignación, a veces, es “algo aprendido, no inherente” (Hornby 1986: 82).

- Un teatro que hace cómplice al público a través de los apartes, pero para que comparta la forma de pensar de la autora, un poco distinta de la de los dramaturgos del momento, aunque no por ello equivocada.

- Un teatro que estereotipa a los personajes (gracioso como cobarde, padre/viejo como defensor del honor y que obliga a las hijas a matrimonios concertados), pero que quiere dejar de ser así.

- Un teatro que rompe la cuarta pared, pero no como mero juego o recurso teatral, sino para dar su opinión, para hacer partícipe al mismo público de lo que esta dramaturga piensa y escribe.

- $Y$, en definitiva, un teatro que, para esta escritora, se ha quedado ya viejo y que quiere renovar, demostrándonos sus múltiples cualidades y nombrándonos a "más de un millar" de autoras que la precedieron.

Concluimos, por tanto, que esta dramaturga áurea no está conforme, parece ser, con la manera de hacer teatro y de pensar que tienen los hombres de su época, y quiere y necesita transgredir las normas para explicarnos cómo lo concibe ella, cosa que hace a través de la metateatralidad, por ejemplo.

\section{REFERENCIAS BIBLIOGRFÁFICAS}

Abel, L., Metatheatre. A New View of Dramatic Form, New York, Hill and Wang, 1963.

Abuín González, Á., "Juego, distancia y público: sobre el concepto de metateatro", Paisaje, juego y multilingüismo: X Simposio de la Sociedad Española de Literatura General y Comparada. Editores D. Villanueva y F. Cabo, Santiago de Compostela, Universidad de Santiago de Compostela, 1996, pp. 13-25. 
El narrador en el teatro. La mediación como procedimiento en el discurso teatral del siglo XX, Santiago de Compostela, Universidad de Santiago de Compostela, 1997.

Arboleda, C. A., Teoría y formas del metateatro en la "Commediadell'Arte", el "Quijote" y algunas obras dramáticas de Cervantes, Syracuse, Syracuse University, 1990.

Teoría y forma del metateatro en Cervantes, Salamanca, Universidad de Salamanca, 1991.

Balestrino, G., "Calderón y el metatetarto: abismación trampantojo y apoteosis del comediante en Mojiganga del mundinova", Teatro de palabras. Revista sobre teatro áureo, 5 (2011), pp. 119-141. http://www.uqtr.ca/teatro/teapal/TeaPalNum05.html.

Bel Enguix, G., Jiménez López, M. J. y Rodríguez Campillo, M. J., “El disfraz varonil en el teatro español de los Siglos de Oro", Revista del Departamento de Filologías Románicas de la URV: Triangle, 4 (2011), pp.69-85.

Caro, A., "El conde Partinuplés", Women'sacts. Plays by women dramatists of Spain's Golden Age. Editora T. Scott Soufas, Kentucky, The University Press of Kentucky, 1997, pp. 137-162.

, Valor, agravio y mujer, Madrid, Biblioteca de Escritores Castalia, 1993.

Cervantes, M. de, Don Quijote de la Macha, Madrid, Planeta, 1996.

Couderc, C., "Ironie et métathéâtredans la Comedia Nueva”, Métathéâtre, théâtredans le théâtre et la folie. Editor J. C. Garrot Zambrano, Tours, Centre d'Études Súperieurs de la Renaissance (Université François-Rabelais de Tours), 2010, pp. 89-110.

Ebersole, A. V., Sobre arquetipos, símbolos y metateatro, Valencia, Albatros, 1988.

García Barrientos, J. L., Cómo se comenta una obra de teatro, México, Paso de Gato, 2012.

Garrot Zambrano, J. C., "Le diablecommeauteur et metteur en scène, dans les Auto Sacramentales de Calderón de la Barca", Métathéâtre, théâtredans le théâtre et la folie. Tours, Centre d'Études Súperieurs de la Renaissance (Université François-Rabelais de Tours), 2010, pp. 111-130.

Gray, M., Claves y estrategias metateatrales. Una propuesta para el estudio y práctica del Metateatro en la contemporaneidad, Madrid, O Grelo Publicaciones, 2011.

Hermenegildo, A., "Mirar en cadena: artificios de la metateatralidad cervantina", Cervantes y la puesta en escena de la sociedad de su tiempo (Actas del Coloquio de Montreal, 1997). Editores C. Poupeney Hard, A. Hermenegildo y C. Oliva, Murcia, Universidad de Murcia, 1999, pp.77-92.

Hernández Valcárcel, C., "Algunos aspectos del teatro dentro del teatro en Lope de Vega", Anales de Filología Hispánica, 4 (1988), pp. 75-96.

Hornby, R., Drama, Metadrama and Perception, London/Toronto, Associated University Presses, 1986. 
Izquierdo Valladres, R., "La función del aparte en el teatro de Cervantes. La comedia de La entretenida", Cervantes y la puesta en escena de la sociedad de su tiempo (Actas del Coloquio de Montreal, 1997). Editores C. Poupeney Hard, A. Hermenegildo y C. Oliva, Murcia, Universidad de Murcia, 1999, pp. 121-138.

Jódar Peinado, M. P., Metateatro español: estudio del concepto y de su presencia en cien textos teatrales de los siglos XX y XXI, Tesis doctoral de la Universidad de Salamanca, Departamento de literatura Española e Hispanoamericana, 2016.

Larson, C., "El metateatro, la comedia y la crítica: hacia una nueva interpretación", Actas del X Congreso de la Asociación Internacional de Hispanistas, 1989.

Lope de Vega, Arte Nuevo de hacer comedias en este tiempo, Editor E. García Santo-Tomás, Madrid, Cátedra, 2006 (1609).

López de Abiada, J. M., "La cara oculta de la letra: ejemplos de contralenguaje en El Quijote, El Burlador de Sevilla y la picaresca", Siglo de Oro-Decadencia. La cultura y la política de España en la primera mitad del siglo XVII. Editores H. Duchardt y C. Strosetzki, Köln-Weiman-Wien, BöhlanVerlag, 1996, pp. 19-32.

---------------, “Hacia Cervantes: de formas, contraformas y juegos de espejos en el teatro", El teatro dentro del teatro. Cervantes, Lope, Tirso y Calderón. Editores I. AndrésSuárez, J.M. López de Abiada y P. Ramírez Molas, Madrid, Verbum, 1997, pp. 31-47. Pavis, P., Diccionario del teatro, Barcelona, Paidós, 1998.

Risco Suárez, N., "Ana Caro de Mallén, la musa sevillana: una periodista feminista en el Siglo de Oro", Revista científica de información y comunicación, Sevilla, Universidad de Sevilla, 2 (2005), pp. 105-120.

Schlueter, J., Metafictional Characters in Modern Drama, New York, Columbia University Press, 1979.

Schmeling, M., Métathéâtre et intertexte. Aspects du théâtre dans le theater, París, Lettres Modernes, 1982.

Sosa, M. B. y Balestrino, G., "La metateatralidad en la dramaturgia española del XVII", Consejo de Investigación de la Universidad Nacional de Salta. Salta, Universidad Nacional de Salta, 2011. 